\title{
Minireview
}

\section{Epigenetics provides a new generation of oncogenes and tumour-suppressor genes}

\author{
M Esteller*,I \\ 'Cancer Epigenetics Laboratory, 3rd Floor, Molecular Pathology Programme, Spanish National Cancer Centre (CNIO), Melchor Fernandez Almagro 3, \\ 28029 Madrid, Spain
}

Cancer is nowadays recognised as a genetic and epigenetic disease. Much effort has been devoted in the last 30 years to the elucidation of the 'classical' oncogenes and tumour-suppressor genes involved in malignant cell transformation. However, since the acceptance that major disruption of DNA methylation, histone modification and chromatin compartments are a common hallmark of human cancer, epigenetics has come to the fore in cancer research. One piece is still missing from the story: are the epigenetic genes themselves driving forces on the road to tumorigenesis? We are in the early stages of finding the answer, and the data are beginning to appear: knockout mice defective in DNA methyltransferases, methyl-CpG-binding proteins and histone methyltransferases strongly affect the risk of cancer onset; somatic mutations, homozygous deletions and methylation-associated silencing of histone acetyltransferases, histone methyltransferases and chromatin remodelling factors are being found in human tumours; and the first cancer-prone families arising from germline mutations in epigenetic genes, such as hSNF5/INII, have been described. Even more importantly, all these 'new' oncogenes and tumour-suppressor genes provide novel molecular targets for designed therapies, and the first DNA-demethylating agents and inhibitors of histone deacetylases are reaching the bedside of patients with haematological malignancies.

British Journal of Cancer (2006) 94, I79- 183. doi:I0.1038/sj.bjc.66029I8 www.bjcancer.com

Published online 10 January 2006

(c) 2006 Cancer Research UK

Keywords: epigenetics; DNA methylation; histones; chromatin

\section{CANCER AS AN EPIGENETIC DISEASE}

Great effort has been directed in recent years towards understanding the establishment and relevance of aberrant epigenetic patterns in human tumours. For DNA methylation, it is known that two apparently contrasting phenomena coexist in the cancer cell: a profound loss of global 5-methylcytosine genomic content with discrete areas of dense hypermethylation (Jones and Baylin, 2002; Feinberg and Tycko, 2004; Esteller, 2005a). Overall hypomethylation takes place predominantly in DNA repetitive and endoparasitic sequences and has been linked to the generation of chromosomal instability (Feinberg and Tycko, 2004; Esteller, 2005a). On the other hand, hypermethylation occurs in the CpG islands located in the promoters of certain tumour-suppressor genes, such as $\mathrm{p} 16^{\mathrm{INK} 4 \mathrm{a}}$, BRCA1 or hMLH, leading to gene silencing (Jones and Baylin, 2002; Esteller, 2005a).

Histones are another key player in epigenetics. Today they are recognised as having a primary role in the control of gene expression and chromatin structure and are partners closely involved with the DNA methylation machinery (Fraga and Esteller, 2005). Our knowledge of the behaviour of histones in cancer cells is slight compared with that of DNA methylation. We know that certain histone modifications participate in tumour-suppressor

\footnotetext{
*Correspondence: Dr M Esteller; E-mail: mesteller@cnio.es

URL: http://grupos.cnio.es/epigenetica/

Received 21 October 2005; revised 25 November 2005; accepted 28 November 2005; published online 10 January 2006
}

gene silencing, in conjunction with $\mathrm{CpG}$ island hypermethylation (Fahrner et al, 2002; Ballestar et al, 2003) or in its absence, such as the case of $\mathrm{p} 21^{\mathrm{WAF} 1}$. Most importantly, we have recently demonstrated that human tumours undergo an overall loss of monoacetylation of lysine 16 and trimethylation of lysine 20 in the tail of histone H4. These two histone-modification losses can be considered as almost universal epigenetic markers of malignant transformation (Fraga et al, 2005), as has now been accepted for global DNA hypomethylation and CpG island hypermethylation. Certain histone acetylation and methylation marks may have prognostic value (Seligson et al, 2005).

Finally, we should not forget that DNA methylation and histone modifications are not isolated events, but occur in higher-order chromatin structure. Nucleosomes, formed by DNA wrapping around an octamer of histones, are the champions of that league. Multi-subunit complexes, such as those constituted by the SWI/ SNF proteins, use the energy of ATP to mobilise nucleosomes and allow the access of the transcriptional machinery (Gibbons, 2005); or massive repressive complexes counteract SWI/SNF functions, as does the polycomb group gene family (Valk-Lingbeek et al, 2004). In the end, the impact on gene expression in cancer cells is massive and the normal epigenetic programming of the healthy cell becomes merely a faint memory.

Never the less, several pieces of the jigsaw are still missing. Are there molecular alterations acting as 'dark horses' behind this distorted epigenetic pattern? Could the epigenetic genes turn out to be the next generation of oncogenes and tumour-suppressor 
genes? Could these genes be targeted with new drugs? Let us review the data that is summarised in Figure 1 and Table 1.

\section{GENES MEDIATING THE DISRUPTION OF DNA METHYLATION}

It has been known for a long time that there is more enzymatic DNA methyltransferase activity overall in tumours than in normal tissues (Esteller, 2005a,b). This finding has been supported by the molecular characterisation of the genes encoding several DNA methyltranferases (DNMT1, DNMT3a, DNMT3b, DNMT3L and DNMT2), which has shown that the number of mRNA transcripts of DNMT1 (the classical methylation maintenance enzyme) and DNMT3b (the de novo methylation enzyme) are greater in several solid and haematological malignancies (Esteller, 2005a).

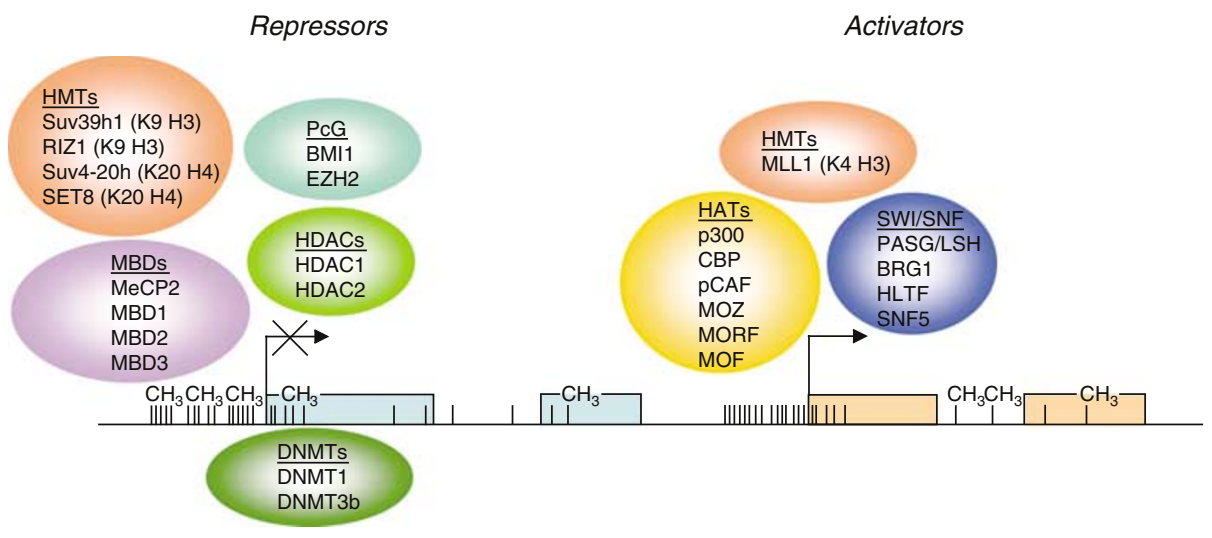

Tumour-suppressor gene

Oncogene

Figure I Epigenetic proteins that contribute to human tumorigenesis. Silencing of a classical tumours suppressor gene involves the recruitment of a transcriptional repressor machinery to the corresponding promoter CpG island, such as DNA methyltransferases (DNMT), methyl-CpG-binding proteins (MBD), histone methyltransferases for lysine 9 of histone H3 (HMT K9 H3), histone deacetylases (HDAC) and polycomb (PcGs) complexes. In the other side of the coin, the active expression of oncogenes in human cancer requires a potent transcriptional activation machinery, such as the one constituted by the chromatin-remodelling factors SWI/SNF, histone acetyltransferases (HATs) and histone methyltransferases for lysine 4 of histone H3 (HMT K4 H3).

Table I A selected list of epigenetic genes disrupted in human cancer and additional potential candidates

\begin{tabular}{|c|c|c|c|}
\hline Gene & Function & Alteration & Tumour profile \\
\hline DNMT3b & DNA methyltransferase & Overexpression & Multiple types \\
\hline $\mathrm{MBD} 2$ & Methyl-CpG-binding protein & Overexpression, rare mutations & Multiple types \\
\hline MBDI & Methyl-CpG-binding protein & Overexpression, rare mutations & Multiple types \\
\hline MBD3 & Methyl-CpG-binding protein & Overexpression, rare mutations & Multiple types \\
\hline MBD4 & Methyl-CpG-binding protein & Inactivating mutations in MSI+ & Colon, stomach, endometrium \\
\hline pCAF & Histone acetyltransferase & Rare mutations & Colon \\
\hline MOZ & Histone acetyltransferase & Translocations & Haematological malignancies \\
\hline MORF & Histone acetyltransferase & Translocations & Haematological malignancies \\
\hline MOF & Histone acetyltransferase & Unknown & Unknown \\
\hline $\mathrm{HDACl}$ & Histone deacetylase & Imbalanced expression & Multiple types \\
\hline HDAC2 & Histone deacetylase & Imbalanced expression & Multiple types \\
\hline SIRTI & Histone deacetylase & Unknown & Unknown \\
\hline BMII & Polycomb-group protein & Gene amplification, overexpression & Haematological malignancies, brain \\
\hline $\mathrm{EZH} 2$ & Polycomb-group protein & Gene amplification, overexpression & Multiple types \\
\hline EMSY & Chromatin-remodelling factor & Gene amplification, overexpression & Breast \\
\hline BRMSI & Chromatin-remodelling factor & Loss of expression & Breast \\
\hline MTAI & Chromatin-remodelling factor & Overexpression & Breast, haematological malignancies \\
\hline MTA3 & Chromatin-remodelling factor & Overexpression & Breast, haematological malignancies \\
\hline PASG/LSH & SWI/SNF family protein & Mutation & Haematological malignancies \\
\hline BRGI & SWI/SNF family protein & Homozygous deletion, mutation & Lung \\
\hline HLTF & SWI/SNF family protein & CpG island hypermethylation & Multiple types \\
\hline SNF5 & SWI/SNF family protein & Somatic and germline mutations & Rhabdoid tumours \\
\hline
\end{tabular}

$\mathrm{MSI}+=$ microsatellite instable tumours. 
Balanced DNMT activity is most important for the prevention of cell transformation. The genetic disruption of two DNMTs, DNMT1 and DNMT3b, in a cancer cell line induces demethylation of all known hypermethylated tumour-suppressor genes (Rhee et al, 2002; Paz et al, 2003) and remarkably slow growth (Rhee et al, 2002). Somatic DNMT mutations have not so far been described in human tumours, although DNMT1 is located in $19 \mathrm{p} 13.3$, a region of common loss of heterozygosity in human tumours. DNMT3b germline mutation are responsible for the immunodeficiency centromeric instability-facial anomalies (ICF) syndrome, the cancer risk of which is not known, while no DNMT1 germline mutation in any genetic syndrome has so far been reported. Results obtained in mouse models again reflect the need for well-adjusted DNMT function to maintain cellular homeostasis: DNMT1 knockout mice are 'protected' against the development of colorectal adenomas when crossed with APC-deficient mice (Laird et al, 1995), but they are 'prone' to develop lymphomas in the context of mice susceptible to this type of neoplasia (Eden et al, 2003). These latter results may be explained if lymphomas rely predominantly on chromosomal instability dependent on genomic DNA hypomethylation, while colon tumours rely more on the CpG island methylation status of tumour-suppressor genes (Yamada et al, 2005).

Something has to read the DNA methylation markers. The most likely candidates are transcriptional repressors that have an appetite for methylated CpGs. These are the methyl-CpG-binding domain proteins (MBDs) (Esteller, 2005a). MBDs are important 'translators' between DNA methylation and histone modifier genes that establish a transcriptionally inactive chromatin environment. This family of proteins consists of five well-characterised members (MeCP2, MBD1, MBD2, MBD3 and MBD4) (Esteller, 2005a). MBD proteins are associated with hypermethylated $\mathrm{CpG}$ island promoters of tumour-suppressor genes and their transcriptional silencing (Esteller, 2005a), showing remarkable specificity in vitro (Fraga et al, 2003) and in vivo (Ballestar et al, 2003; Klose et al, 2005).

Individual loss of MeCP2, MBD1, MBD2, for which single knockout mice are viable, do not appear to affect tumour formation significantly (Esteller, 2005a), which suggests that the remaining MBDs may compensate for the function of the missing one. However, deficiency of MBD2 suppresses intestinal tumorigenesis in an Mbd2-knockout mouse derived from a lineage with an autosomal-dominantly inherited predisposition to multiple intestinal neoplasia (Min) (Sansom et al, 2003). We can hypothesise that the absence of MBD2 produces a 'leak' in the $\mathrm{CpG}$ island hypermethylation silencing of tumour-suppressor genes, thereby partially aborting aberrant cancer growth. This may not be universal for all tumour types and in this regard deficiency of MBD2 does not enhance lymphomagenesis in p53deficient mice (Sansom et al, 2005). Expression analysis of MBD proteins in tumours has revealed increased overall levels associated with enhanced proliferation (Esteller, 2005a). Mutations in MBDs do occur in sporadic tumours, albeit rarely (Bader et al, 2003). MBD4 is an exception and is frequently targeted by inactivating frameshift mutations in microsatellite-unstable tumours (Riccio et al, 1999). However, we should keep in mind that MBD4 is unusual: it has a glycosylase domain that removes thymidine from $\mathrm{T}: \mathrm{G}$ mismatches.

\section{GENES MEDIATING THE DISRUPTION OF HISTONE MODIFICATIONS}

A first draft of an aberrant histone modification signature for human cancer has been produced (Fraga et al, 2005; Fraga and Esteller, 2005; Seligson et al, 2005). The next task is to identify the molecules involved in its establishment: histone acetyltransferases (HATs), histone methyltransferases (HMTs) and histone deacetylases (HDACs).
With respect to histone acetylation, we have found a loss of recruitment of a family of the specific K-16 HATs MOZ, MOF and MORF to DNA-repetitive sequences in cancer cells (Fraga et al, 2005). These HATs are already altered in leukaemias by the generation of fusion proteins such as MOZ-CBP and MORF-CBP that are also associated with significant global losses of acetylation of K16-H4 (Fraga et al, 2005). What makes the case even more interesting is that the other partner of the fusion protein generated is usually CBP or p300, two other HATs with numerous substrates, but that do not act on lysine 16 of H4 (Fraga and Esteller, 2005). A tumour-suppressor role for these global HATs has been strongly suggested from many sources: CBP, p300 and pCAF somatic mutations have been described in primary human tumours (Gayther et al, 2000; Ozdag et al, 2002; Ionov et al, 2004; Kishimoto et al, 2005); patients with Rubinstein - Taybi syndrome, caused by germline mutations in the CBP gene, have an increased tendency to develop tumours at an early age (Gibbons, 2005); and CBP heterozygous mice develop haematological tumours (Gibbons, 2005).

In the case of HDAC, the deacetylation of K16-H4 seems to be particularly closely regulated: in yeast, Sir2 deacetylates this residue, and its human homologue, Sirtuin 1 (SIRT1), also deacetylates the tumour-suppressor protein p53, thereby establishing another link with cancer. We can view the picture from this angle and hypothesise that there is increased recruitment of SIRT1 to the $\mathrm{K} 16-\mathrm{H} 4$ position in repeat DNA sequences in the transformed cell. In this regard, overexpression of SIRT1 is observed in leukemia cells (Bradbury et al, 2005). For HDACs with a broader deacetylation specificity than SIRT1, such as HDAC1 and HDAC2, no somatic mutations in tumours have been described, but a dysregulated expression seems to be a common feature of human neoplasia (Gibbons, 2005).

A similar scenario could be proposed for the trimethylation of lysine 20 of $\mathrm{H} 4$ (Fraga et al, 2005). This reaction is catalysed by the HMTs Suv4-20h1 and Suv4-20h2, in addition to PR/SET7-SET8 (Fraga and Esteller, 2005). These enzymes can be targets for disruption in cancer cells, as occurs with another HMT, MLL1, which is translocated to multiple partners in haematological malignancies (Fraga and Esteller, 2005). The loss of trimethylation of histone $\mathrm{H} 4$ in cancer cells might be a consequence of a deficiency of these enzymatic activities in tumours, and/or a lack of recruitment to heterochromatic regions, where most of the histones containing such modifications are localised. We should keep in mind that mice deficient in SUV39H1 HMTs (which target lysine 9 of histone H3) have increased chromosomal instability and tumour risk (Peters et al, 2001) and another K9-H3 histone methyltransferase, RIZ1, undergoes CpG island hypermethylationassociated silencing in many tumour types (Esteller, 2005a). Lack of HMTs specific to $\mathrm{K} 20-\mathrm{H} 4$ has not yet been described in tumours, but all these issues can now be addressed with new tools, such as specific antibodies against Suv4-20h (Fraga et al, 2005).

\section{GENES MEDIATING THE DISRUPTION OF CHROMATIN REMODELLING}

Polycomb-group (PcG) and trithorax-group (trxG) genes are epigenetic silencers and activators for gene transcription, respectively (Valk-Lingbeek et al, 2004; Raaphorst, 2005). Both are part of multitask protein complexes including HDAC and HMTs activities. In the case of the human homologue of trithorax, MLL, I have already mentioned the existence of translocations that generate transforming fusion proteins (Gibbons, 2005). For PcG in human there are two complexes, polycomb repressive complex 1 (PRC1) and 2 (PRC2), which contain the BMI1 and enhancer of zeste homologue 2 (EZH2) oncogenes, respectively (Valk-Lingbeek et al, 2004; Raaphorst, 2005). BMI1 downregulates the expression of tumour-suppressor genes, such as p16 $6^{\mathrm{INK} 4 \mathrm{a}}$ and $\mathrm{p} 14^{\mathrm{ARF}}$ 
(Valk-Lingbeek et al, 2004), transgenic mice have a high predisposition to lymphomagenesis, subtypes of human lymphomas harbour BMI1 gene amplification and overexpression and it induces cell immortalisation (Valk-Lingbeek et al, 2004; Raaphorst, 2005). EZH2 undergoes gene amplification in several tumour types (Bracken et al, 2003), it is overexpressed in prostate and breast cancers, and its downregulation leads to growth inhibition (Raaphorst, 2005).

Another powerful epigenetic repressor family of chromatinremodelling factors is the Tudor domain 'Royal Family' (HughesDavies et al, 2003). Two of its members, HP1 and BS69, bind to EMSY. The latter gene is a critical component in breast cancer development in the BRCA2 pathway. Most importantly, EMSY behaves as an oncogene in mammary neoplasm, where it shows gene amplification (Hughes-Davies et al, 2003). The list of targeted epigenetic repressors also includes Breast Cancer Metastasis Suppressor 1 (BRMS1), which is able to inhibit metastasis without 'touching' tumorigenesis itself (Meehan and Welch, 2003). BRMS1 joins the mSin3a HDAC complexes to silence the targeted genes (Meehan and Welch, 2003). An opposing force to BRMS1 is the group of metastasis-associated genes (MTAs). MTA1, MTA2, and MTA3 are components of the nucleosome remodelling and deacetylation complex, as a part of the NuRD complex. Metastasis-associated gene 1 overexpression is associated with the most malignant behaviour in several human tumours. Metastasisassociated gene 3 has a predominant role in lymphoma and breast cancer, in the latter leading to aberrant expression of the transcriptional repressor Snail and loss of expression of the celladhesion molecule E-cadherin, an event associated with invasive growth of breast cancers (Fujita et al, 2003).

The best-recognised chromatin remodelling 'force' is the SWI/ SNF family of ATP-hydrolysing enzymes (Gibbons, 2005). These are multiprotein complexes, as we have seen in the case of the PcG, but in this case with transcriptional activation properties. Among the many members of the SWI/SNF family, four are involved with cancer development: PASG/LSH, BRG1, HLTF and SNF5. Potential mutations of PASG/LSH have been identified in leukaemia (Lee et al, 2000); BRG1 genetic alterations occur in several tumour types and the reintroduction of the gene inhibits cell growth (Medina et al, 2005); helicase-like transcription factor (HLTF) undergoes methylation-associated silencing in different neoplasms (Esteller, 2005a); and SNF5 shows inactivating somatic and germline mutations in malignant rhabdoid tumours (Imbalzano and Jones, 2005).

\section{TARGETING EPIGENETIC GENES IN CANCER THERAPY}

The 'holy grail' of current research in cancer therapy is the design of specific drugs against molecular alterations found only in the transformed cell, such as mutations in oncogenes. Epigenetics can offer many new targets for this approach. However, only two types of epigenetic drugs, neither of which is very specific, have nowadays a real impact: DNA-demethylating agents and histone deacetylase inhibitors (HADCis) (Villar-Garea and Esteller, 2004; Esteller, 2005b). We have to be patient with other potential epigenetic drugs, such as histone acetyltransferase inhibitors, including anacardic acid, curcumin, and peptide CoA conjugates; in addition to undisclosed histone methyltransferase inhibitors or those HDACis that are specific for SIRT1 (class III HDAC), such as nicotinamide and splitomycin.
Of the class of DNA-demethylating agents, the first drug used to inhibit DNA methylation was 5-azacytidine (Vidaza). This substance causes covalent arrest of DNMTs, resulting in cytotoxicity. 5-Azacytidine was tested for its usefulness as an antileukaemic drug before its demethylating activity was known (Esteller, 2005b). The analogue 5-aza-2'-deoxycytidine (Decitabine) is one of the most commonly used demethylating drugs in assays with cultured cells. Zebularine is another recently developed cytidine analogue (Yoo et al, 2004). It forms a covalent complex with DNA methyltransferases (Yoo et al, 2004). Furthermore, zebularine has also shown promising antitumoral effects in xenografts (Yoo et al, 2004) and thymic lymphomas (Herranz et al, 2005) in mice. Perhaps the most interesting feature of this DNA-demethylating agent is that it is chemically stable and of low toxicity (Yoo et al, 2004; Herranz et al, 2005), and can be taken orally. It is in the field of haematological malignancies that DNA-demethylating agents have had their greatest success so far, especially in high-risk myelodysplastic syndrome using 5-aza-2-deoxycytidine (Esteller, 2005b). In 2004, the FDA approved the use of 5-azacytidine (Vidaza) for the treatment of all myelodysplastic syndrome subtypes.

On the other hand, naturally occurring and synthetic HDACis are also the focus of interest because of their great potential utility against cancer. Overall, HDACis manifest a wide range of activities against all HDACs. These compounds can be classified into the following groups according to their chemical nature: hydroxamic acids, such as trichostatin A, SAHA, PXD101 and NVP-LAQ-824; carboxylic acids, such as sodium valproate and butyrate; benzamides, such as MS-272 and others, including trapoxins and FK228 (Villar-Garea and Esteller, 2004). It is believed that the anticancer effects of HDACis are mediated by the reactivation of the expression of tumour-suppressor genes. However, the treatment of cancer cell lines with HDACis has pleiotropic effects inducing differentiation, cell-cycle arrest and apoptosis. In this regard, the observation that cancer cells have lost monoacetylated lysine 16 histone H4 (Fraga et al, 2005) implies a new molecular pathway that may explain the beneficial effects of HDAC inhibitors because these compounds may promote the restoration of normal histone $\mathrm{H} 4$ acetylation levels in the whole cell, restoring the normal chromatin status of repetitive DNA sequences (Fraga et al, 2005). It is clear from in vitro, preclinical studies and ongoing clinical trials that HDACis have enormous potential as anticancer drugs. In this regard, SAHA may soon be approved for the treatment of cutaneous lymphoma.

\section{CONCLUSIONS}

Cancer is a genetic and epigenetic disease. We cannot study and explore one field and ignore the other. The overall disruption of the epigenetic landscape is the most common feature of all human tumours. This includes global loss of genomic DNA methylation, local CpG island hypermethylation-associated gene silencing and a characteristic histone modification pattern. Stochastic and selective forces drive the whole process, and in the same way as in the cell cycle, apoptosis and DNA repair genes are targeted, genes involved in DNA methylation, histone modification and chromatin remodelling also become disrupted. Some of these will act as oncogenes, others as tumour-suppressor genes. Some will be altered by genetic lesions, others by epigenetic lesions. Ultimately, we will have to find better drugs to combat both processes.

\section{REFERENCES}

Bader S, Walker M, McQueen HA, Sellar R, Oei E, Wopereis S, Zhu Y, Peter A, Bird AP, Harrison DJ (2003) MBD1, MBD2 and CGBP genes at chromosome $18 \mathrm{q} 21$ are infrequently mutated in human colon and lung cancers. Oncogene 22: 3506-3510 
Ballestar E, Paz MF, Valle L, Wei S, Fraga MF, Espada J, Cigudosa JC, Huang TH, Esteller M (2003) Methyl-CpG binding proteins identify novel sites of epigenetic inactivation in human cancer. EMBO J 22: 6335-6345

Bracken AP, Pasini D, Capra M, Prosperini E, Colli E, Helin K (2003) EZH2 is downstream of the pRB-E2F pathway, essential for proliferation and amplified in cancer. EMBO J 22: $5323-5335$

Bradbury CA, Khanim FL, Hayden R, Bunce CM, White DA, Drayson MT, Craddock C, Turner BM (2005) Histone deacetylases in acute myeloid leukaemia show a distinctive pattern of expression that changes selectively in response to deacetylase inhibitors. Leukemia 19: 1751-1759

Eden A, Gaudet F, Waghmare A, Jaenisch R (2003) Chromosomal instability and tumors promoted by DNA hypomethylation. Science 30: 455

Esteller M (2005a) Aberrant DNA methylation as a cancer-inducing mechanism. Annu Rev Pharmacol Toxicol 45: 629-656

Esteller M (2005b) DNA methylation and cancer therapy: new developments and expectations. Curr Opin Oncol 17: 55-60

Fahrner JA, Eguchi S, Herman JG, Baylin SB (2002) Dependence of histone modifications and gene expression on DNA hypermethylation in cancer. Cancer Res 62: 7213-7218

Feinberg AP, Tycko B (2004) The history of cancer epigenetics. Nat Rev Cancer 4: $143-153$

Fraga MF, Ballestar E, Montoya G, Taysavang P, Wade PA, Esteller M (2003) The affinity of different MBD proteins for a specific methylated locus depends on their intrinsic binding properties. Nucleic Acids Res 31: $1765-1774$

Fraga MF, Ballestar E, Villar-Garea A, Boix-Chornet M, Espada J, Schotta G, Bonaldi T, Haydon C, Ropero S, Petrie K, Iyer NG, Perez-Rosado A, Calvo E, Lopez JA, Cano A, Calasanz MJ, Colomer D, Piris MA, Ahn N, Imhof A, Caldas C, Jenuwein T, Esteller M (2005) Loss of acetylation at Lys16 and trimethylation at Lys20 of histone $\mathrm{H} 4$ is a common hallmark of human cancer. Nat Genet 37: $391-400$

Fraga MF, Esteller M (2005) Towards the human cancer epigenome: a first draft of histone modifications. Cell Cycle 4: 144-148

Fujita N, Jaye DL, Kajita M, Geigerman C, Moreno CS, Wade PA (2003) MTA3, a Mi-2/NuRD complex subunit, regulates an invasive growth pathway in breast cancer. Cell 113: 207-219

Gayther SA, Batley SJ, Linger L, Bannister A, Thorpe K, Chin SF, Daigo Y, Russell P, Wilson A, Sowter HM, Delhanty JD, Ponder BA, Kouzarides T, Caldas C (2000) Mutations truncating the EP300 acetylase in human cancers. Nat Genet 24: 300-303

Gibbons RJ (2005) Histone modifying and chromatin remodelling enzymes in cancer and dysplastic syndromes. Hum Mol Genet 14(1): R85- R92

Herranz M, Martín-Caballero J, Fraga MF, Ruiz-Cabello J, Flores JM, Desco M, Marquez V, Esteller M (2005) The novel DNA methylation inhibitor zebularine is effective against the development of murine T-cell lymphoma. Blood, in press

Hughes-Davies L, Huntsman D, Ruas M, Fuks F, Bye J, Chin SF, Milner J, Brown LA, Hsu F, Gilks B, Nielsen T, Schulzer M, Chia S, Ragaz J, Cahn A, Linger L, Ozdag H, Cattaneo E, Jordanova ES, Schuuring E, Yu DS, Venkitaraman A, Ponder B, Doherty A, Aparicio S, Bentley D, Theillet C, Ponting CP, Caldas C, Kouzarides T (2003) EMSY links the BRCA2 pathway to sporadic breast and ovarian cancer. Cell 115: 523-535

Imbalzano AN, Jones SN (2005) Snf5 tumor suppressor couples chromatin remodeling, checkpoint control, and chromosomal stability. Cancer Cell 7: $294-295$

Ionov Y, Matsui S, Cowell JK (2004) A role for p300/CREB binding protein genes in promoting cancer progression in colon cancer cell lines with microsatellite instability. Proc Natl Acad Sci USA 101: 1273-1278

Jones PA, Baylin SB (2002) The fundamental role of epigenetic events in cancer. Nat Rev Genet 3: 415-428

Kishimoto M, Kohno T, Okudela K, Otsuka A, Sasaki H, Tanabe C, Sakiyama T, Hirama C, Kitabayashi I, Minna JD, Takenoshita S, Yokota J
(2005) Mutations and deletions of the CBP gene in human lung cancer. Clin Cancer Res 11: 512-519

Klose RJ, Sarraf SA, Schmiedeberg L, McDermott SM, Stancheva I, Bird AP (2005) DNA binding selectivity of MeCP2 due to a requirement for A/T sequences adjacent to methyl-CpG. Mol Cell 19: 667-678

Laird PW, Jackson-Grusby L, Fazeli A, Dickinson SL, Jung WE, Li E, Weinberg RA, Jaenisch R (1995) Suppression of intestinal neoplasia by DNA hypomethylation. Cell 81: 197-205

Lee DW, Zhang K, Ning ZQ, Raabe EH, Tintner S, Wieland R, Wilkins BJ, Kim JM, Blough RI, Arceci RJ (2000) Proliferation-associated SNF2-like gene (PASG): a SNF2 family member altered in leukemia. Cancer Res 60: $3612-3622$

Medina PP, Carretero J, Ballestar E, Angulo B, Lopez-Rios F, Esteller M, Sanchez-Cespedes M (2005) Transcriptional targets of the chromatinremodelling factor SMARCA4/BRG1 in lung cancer cells. Hum Mol Genet 14: $973-982$

Meehan WJ, Welch DR (2003) Breast cancer metastasis suppressor 1: update. Clin Exp Metast 20: 45-50

Ozdag H, Batley SJ, Forsti A, Iyer NG, Daigo Y, Boutell J, Arends MJ, Ponder BA, Kouzarides T, Caldas C (2002) Mutation analysis of CBP and PCAF reveals rare inactivating mutations in cancer cell lines but not in primary tumours. Br J Cancer 87: $1162-1165$

Paz MF, Wei S, Cigudosa JC, Rodriguez-Perales S, Peinado MA, Huang TH, Esteller M (2003) Genetic unmasking of epigenetically silenced tumor suppressor genes in colon cancer cells deficient in DNA methyltransferases. Hum Mol Genet 12: 2209-2219

Peters AH, O'Carroll D, Scherthan H, Mechtler K, Sauer S, Schofer C, Weipoltshammer K, Pagani M, Lachner M, Kohlmaier A, Opravil S, Doyle M, Sibilia M, Jenuwein T (2001) Loss of the Suv39h histone methyltransferases impairs mammalian heterochromatin and genome stability. Cell 107: $323-337$

Raaphorst FM (2005) Deregulated expression of Polycomb-group oncogenes in human malignant lymphomas and epithelial tumors. Hum $\mathrm{Mol}$ Genet 14(1): R93-R100

Rhee I, Bachman KE, Park BH, Jair KW, Yen RW, Schuebel KE, Cui H, Feinberg AP, Lengauer C, Kinzler KW, Baylin SB, Vogelstein B (2002) DNMT1 and DNMT3b cooperate to silence genes in human cancer cells. Nature 416: $552-556$

Riccio A, Aaltonen LA, Godwin AK, Loukola A, Percesepe A, Salovaara R, Masciullo V, Genuardi M, Paravatou-Petsotas M, Bassi DE, Ruggeri BA, Klein-Szanto AJ, Testa JR, Neri G, Bellacosa A (1999) The DNA repair gene MBD4 (MED1) is mutated in human carcinomas with microsatellite instability. Nat Genet 23: 266-268

Sansom OJ, Berger J, Bishop SM, Hendrich B, Bird A, Clarke AR (2003) Deficiency of Mbd2 suppresses intestinal tumorigenesis. Nat Genet 34: $145-147$

Sansom OJ, Bishop SM, Bird A, Clarke AR (2005) MBD2 deficiency does not accelerate p53 mediated lymphomagenesis. Oncogene 24: $2430-2432$

Seligson DB, Horvath S, Shi T, Yu H, Tze S, Grunstein M, Kurdistani SK (2005) Global histone modification patterns predict risk of prostate cancer recurrence. Nature 435: 1262-1266

Valk-Lingbeek ME, Bruggeman SW, van Lohuizen M (2004) Stem cells and cancer; the polycomb connection. Cell 118: 409-418

Villar-Garea A, Esteller M (2004) Histone deacetylase inhibitors: understanding a new wave of anticancer agents. Int $J$ Cancer 112: $171-178$

Yamada Y, Jackson-Grusby L, Linhart H, Meissner A, Eden A, Lin H, Jaenisch R (2005) Opposing effects of DNA hypomethylation on intestinal and liver carcinogenesis. Proc Natl Acad Sci USA 102: $13580-13585$

Yoo CB, Cheng JC, Jones PA (2004) Zebularine: a new drug for epigenetic therapy. Biochem Soc Trans 32: 910-912 